\title{
МЕТАМОРФОЗЫ НИКОЛАЕВСКОГО ПСАЛИЯ
}

\author{
Юрий Алексеевич Морозов \\ независимый исследователь, Уфа, Россия \\ E-mail:morozovua1941@gmail.com \\ Михаил Сергеевич Чаплыгин \\ Стерлитамакский историко-краеведческий музей, Стерлитамак, Россия \\ E-mail: msch1979@gmail.com \\ Анатолий Николаевич Усачук \\ Донецкий краеведческий музей, Донецк, Украина \\ E-mail: doold@mail.ru \\ Андрей Валерьевич Вербовский \\ Донецкий краеведческий музей, Донецк, Украина \\ E-mail: verbovskiyy@ro.ru
}

\begin{abstract}
Аннотация. В статье детально рассматривается процесс изготовления и использования желобчатого псалия из Николаевского могильника. Представлены две реконструкции изделия: изначальный вид и вид после поломки и ремонта. Как выясняется, до поломок николаевский псалий по классификации подобных изделий наиболее близок был псалиям усатовского типа. Изготовление не только графической, но и объемной реконструкции псалия позволило предложить своеобразное крепление наносного ремня. После этого объемная реконструкция псалия была сломана нами так, как она сломалась, на наш взгляд, первый раз - вдоль щитка и из обломка изготовлен второй вариант николаевского псалия, который некоторое время продолжал еще служить, пока не сломался - на этот раз окончательно - поперек щитка.
\end{abstract}

Ключевые слова: псалий, изготовление, эксплуатация, мастер, ремонт, реконструкция, ремни оголовья, срубная культура

Цитирование. Морозов Ю.А., Чаплыгин М.С., Усачук А.Н., Вербовский А.В., 2021. Метаморфозы Николаевского псалия // Уфимский археологический вестник. Т.21, №2. C.314-321. DOI: https://doi. org/10.31833/uav/2021.21.2.009

UDC 902.01

Submitted: 20.09 .2021

LBC 63.4

Accepted: 20.10.2021

\section{METAMORPHOSES OF THE NIKOLAEVKA CHEEK PIECE}

\author{
Yuri A. Morozov \\ independent researcher, Ufa, Russia \\ E-mail: morozovua1941@gmail.com \\ Mikhail S. Chaplygin \\ Sterlitamak Museum of Local Lore, Sterlitamak, Russia \\ E-mail:msch1979@gmail.com \\ Anatoly N. Usachuk \\ Donetsk Museum of Local Lore, Donetsk, Ukraine \\ E-mail: doold@mail.ru \\ Andrey V. Verbovsky \\ Donetsk Museum of Local Lore, Donetsk, Ukraine \\ E-mail: verbovskiyy@ro.ru
}

\begin{abstract}
The subject of this article is the grooved check piece fragment, discovered in 2005 in the upper part of the burial 11 of the barrow 1 located on the territory of the Nikolaevsky necropolis. The find was previously analyzed by a group of scholars including R. Ismagil, Y. Morozov and others. However, the result of their study was just a general description of the artefact. The current work presents a more detailed analysis of the find and its features. The check piece was made of the outer shell of the long bone diaphysis of a really large ungulate. It was broken along the central axis through the holes a bit guard and the guard lug. Some parts of the trapezoid bit guard and guard lug have been preserved. The outer surface of the lug has cuts and scrapes. The lug is thinner than the main part of the bit guard and it was deliberately left rough. At one side of the lug there is a protrusion, which was made by carefully cutting and sawing the bone at different angles with a metal blade. The outer surface of the bit guard is smoothen and decorated with a pattern of outlined triangles with adjacent apexes. The lines were made with a metal spike. The patterns were created not with transversal, but with diagonal lines that form triangles on the surface of the cheek piece. In course of the study, we made a graphical reconstruction of the cheek-piece and its three-dimensional model using extruded polystyrene foam. This allowed us to get some insights concerning the belt fasteners of the whole and then broken cheek-piece in use.
\end{abstract}



culture

Keywords: cheek piece, manufacturing, use, repairer, repair, reconstruction, headstall belts, Srubnaya

Citation. Morozov Yu., Chaplygin M., Usachuk A., Verbovsky A. 2021. Metamorphoses of the Nikolaevka cheek piece. Ufimskij arkheologicheskiy vestnik [The Ufa Archaeological Herald]. Vol.21, no. 2, pp. 314-321. (In Russ.). DOI: https://doi.org/10.31833/uav/2021.21.2.009

... Как все меняется! Что было раньше птищей, Теперь лежит написанной страницей ...

Н. Заболоцкий «Метаморфозы»

\section{Введение}

В 2004-2006гг. Ю.А. Морозовым и М.С. Чаплыгиным были исследованы несколько курганов Николаевского могильника (Стерлитамакский район Республики Башкортостан). Довольно оперативно полученные интересные и разновременные данные могильника были опубликованы [Морозов, 2006; Морозов, Чаплыгин, 2007; Исмагил и др., 2009], причем, в монографии, помимо основного текста, присутствовал целый ряд приложений [Куфтерин, Нечвалода, 2009; Сатаев, 2009; Сатаев, Гимранов, 2009; Сулейманов, 2009], позволяющий более полно представить различную информацию по раскопанным курганам.

В 2005 г. в засыпке над центральным погребением 11 в кургане 1 найден фрагмент желобчатого псалия [Морозов, 2006. С. 61; Морозов, Чаплыгин, 2007. С. 56; Исмагил и др., 2009. С. 20-21] (рис. 1, $1-2)$. Краткое трасологическое описание находки было дано в монографии [Исмагил и др., 2009. С. 139-140], но стало очевидно, что псалий требует более пристального внимания. Словесная подача информации по псалию без опоры на схемы и реконструкции, и только один повторяющийся рисунок фрагмента изделия [Морозов, 2006. Рис. 1, 28; Морозов, Чаплыгин, 2007. Рис. 8, 7; Исмагил и др., 2009. Рис. 13,$5 ; 47,10]$ оказались явно недостаточны: в итоговой работе по желобчатым псалиям евразийских степей николаевская находка не определена по типу и помещена в подборку обломков и заготовок желобчатых псалиев с шипами [Бочкарев, Кузнецов, 2010. Рис. 8, 2], хотя псалий бесшипный. ${ }^{1}$ Кроме того, подача полученной трасологической информации по псалию со схемами, фотографиями и реконструкциями позволяет более подробно представить процесс изготовления и эксплуатации изделия, а также исправить допущенные ранее ошибки в описании.

\section{Николаевский псалий: описание}

Николаевский псалий изготовлен из компакты трубчатой кости крупного копытного. Судя по реконструкции первоначального вида псалия (об этом ниже), в качестве сырья использовали диафиз трубчатой кости очень крупного животного (скорее всего, это кость конечности взрослой особи крупного рогатого скота). Псалий сломан вдоль почти по центру через отверстия в планке и щитке. Coхранились части трапециевидной планки (рис. 1 ,
$3 A)$ и щитка (рис. $1,3 Б)$ ). Внешняя поверхность планки несет на себе следы строгания и скобления (рис. 1, 6A). Она чуть утончена по сравнению со щитком и намеренно оставлена неровной. На торце планки сохранился левый боковой выступ (рис. $1,3 B, 5 A, 65$ ), изготовленный довольно аккуратно при помощи подрезки и пиления компакты под разными углами металлическим лезвием. Внешняя поверхность щитка обработана абразивом, специально выровнена и украшена орнаментом в виде прочерченных треугольников, вершины которых соприкасаются. Линии нанесены металлическим острием. В кратком трасологическом описании дана неверная последовательность операций по вырезке орнамента [Исмагил и др., 2009. С. 139]. Не очень хорошо сохранилась продольная линия, ограничивающая орнаментальную зону (рис. $1,3 \Gamma, 6 B$ ) и мы не можем с уверенностью сказать, когда ее нанес мастер (скорее всего, до вырезки поперечных линий). Но начало орнамента на псалии положено не поперечными, а именно диагональными линиями, образовавшими стороны треугольников, а также аккуратной штриховкой этих треугольников: некоторые линии штриховки были позже перечеркнуты резкой поперечных линий (рис. 1, 3Д, 6Г). Давление на острие во время штриховки было меньше, чем при резке поперечных и диагональных линий. Обратим внимание на то, что мастер, видимо, сначала сделал штриховку нижних треугольников - она аккуратнее, а затем - штриховку верхних. В планке одно над другим просверлены два маленьких отверстия. Сверление отверстия на границе планки и щитка (рис. 1, $3 E$, $5 Б$ ) велось с обеих сторон (материал сверла неясен). Сработанность второго отверстия в планке (рис. 1, 3Ж, 5B) не позволила выяснить приемы его изготовления. По вертикальной оси псалия в центре щитка частично сохранились два овальных сильно сработанных отверстия (рис. 1, 43, 4И", $5 \Gamma, 5 Д, 6 Д, 6 Е)$. Ближе к правому торцу щитка по орнаменту изготовлено овальное боковое отверстие (рис. $1,4 K, 5 E, 6 Ж)$. Скорее всего, небольшая неровность внутри этого очень сглаженного работой отверстия (рис. 1, 63) маркирует процесс типичного изготовления овальных отверстий методом последовательного сверления: два или три маленьких круглых отверстия в ряд с подрезкой их в дальнейшем в одно овальное [ср.: Бородовский,

\footnotetext{
${ }^{1}$ Отчасти это и мое упущение, поскольку с П.Ф. Кузнецовым мы, как редакторы сборника 2010 г., плотно работали над текстами глав, а к тому времени я уже держал николаевский псалий в руках (прим. А.Н. Усачука).

${ }^{2}$ Из-за большого количества деталей, которые нужно было отразить на схеме следов изготовления и использования псалия, мы дали рисунок находки дважды, чтобы «разгрузить» схему, где стрелки не накладывались бы друг на друга.
} 

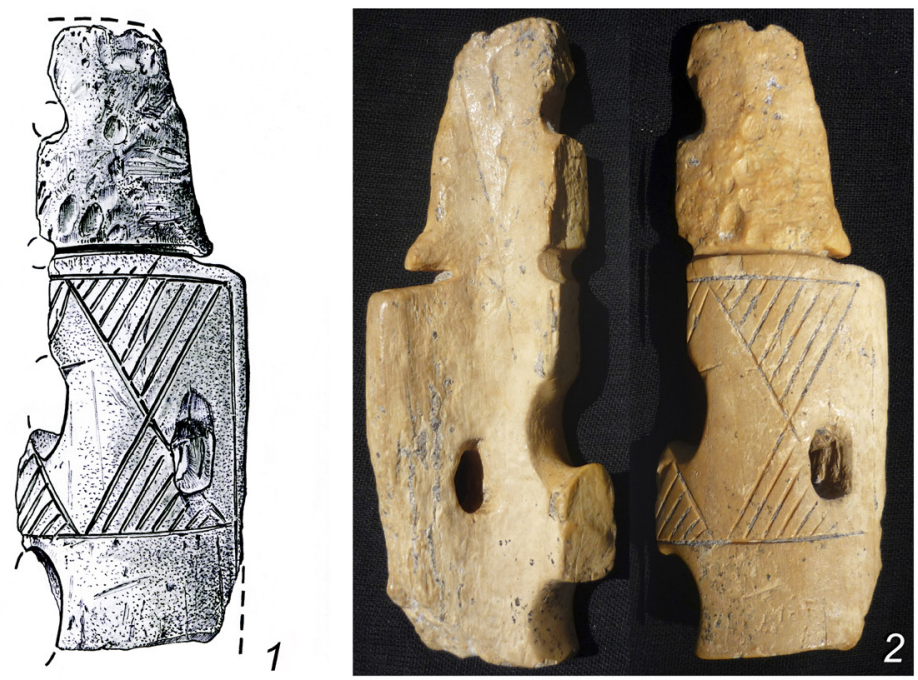

\section{$\mathrm{H}$}
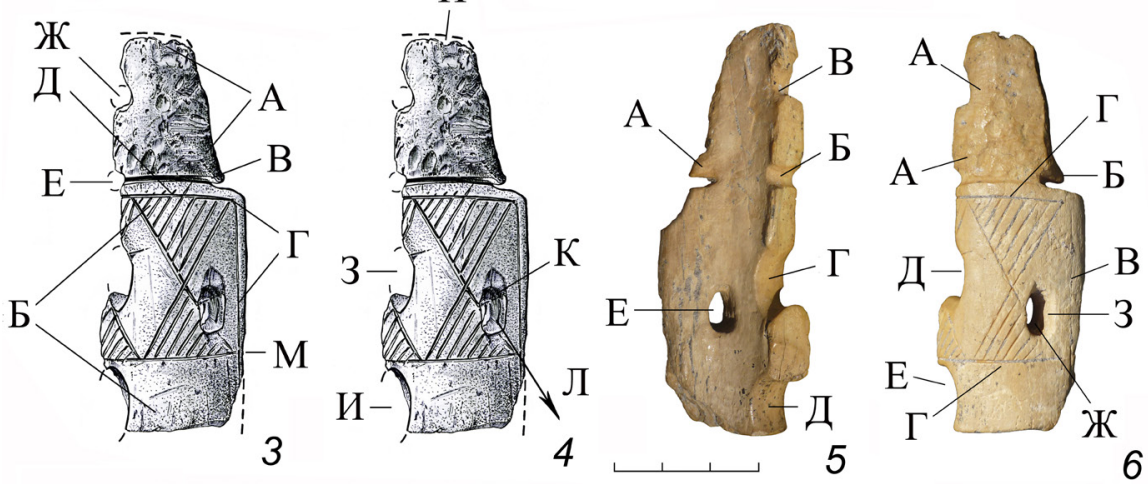

Рис. 1. Фрагмент псалия из засыпки п. 11 кургана 1 Николаевского могильника: 1 - рисунок; 2 - фото (внутренняя и внешняя стороны); 3-6 - схема следов изготовления и использования на псалии

Fig. 1. Cheek piece fragment from the upper part of the burial 11 of the barrow 1 located on the territory of the Nikolaevsky necropolis: 1 -drawing; 2 - photo (inner and outer surface); 3-6 - a scheme of production and use traces at the check piece

1997. С. 88; Усачук, 2013. С. 109, 114]. ${ }^{3}$ Это отверстие, как упоминалось выше, сработано, причем направление сработанности идет вправо вниз (рис. 1, 4Л). Заметим, что фрагмент торца псалия возле бокового отверстия немного утрачен (рис. 1 , $3 M)$, но слом завальцован, то есть псалий продолжали использовать после этой очень небольшой поломки. Внутренняя поверхность псалия залощена до заполировки (рис. $1,2,5)$.

\section{Вопросы}

\section{реконструкции николаевского псалия}

Ранее мы предложили размеры всего изделия [Исмагил и др., 2009. С. 140]. Сейчас, опираясь на графическую реконструкцию (рис. 2, 1), можно скорректировать размеры и более наглядно представить николаевский псалий до поломки его по линии большого количества отверстий - на участке с неравномерной концентрацией напряжений [ср.: Усачук, 2016. С. 27]. Отверстия выстроились вертикально в ряд по центру изделия, поэтому и псалий сломался вдоль почти пополам. Торец планки немного утрачен (рис. $1,4 H$ ), первоначальная длина ее была в рамках $3,1 \mathrm{~cm}$, ширина у основания 4,2 cм, по верхнему торцу $-2,6-2,7 \mathrm{~cm}$. Длина щитка 5,2 см, ширина его реконструирует- ся в пределах 5 см. Общая длина псалия составляла $8,3 \mathrm{~cm}$.

Впрочем, ситуация с николаевским фрагментом псалия на этом не исчерпывается. Псалий до поломки был довольно широким, но очень коротким, имея к тому же два центральных отверстия (рис. 2,1$)$. Безусловно, ниже сломанного овального отверстия шел щиток, но на какую длину?

Продольная поломка изделия почти пополам, на наш взгляд, являлась вторичной. Первоначально псалий сломался поперек через нижнюю часть овального отверстия в щитке. Если представить, что первая поломка «забрала» очень небольшую по ширине часть щитка (в пределах 2,5-2,6см), то перед нами - остатки своеобразного псалия с двумя центральными отверстиями. Недавно подобные изделия были выделены в особую разновидность щитковых псалиев и получили название «пластинчатые» [Бочкарев, Кузнецов, 2019. C.50]. Исследователи отмечают, что они «ближе всего стоят к бесшипным вариантам желобчатых псалиев» [Бочкарев, Кузнецов, 2019. С.50]. Но у николаевского псалия кроме гипотетических двух центральных отверстий, нет никаких признаков пластинчатых псалиев. Во-первых, псалий

${ }^{3}$ Не исключено, что так делались и овальные отверстия в центре щитка, но их фрагментарность и сильная сработанность не сохранили следов возможной подрезки. 


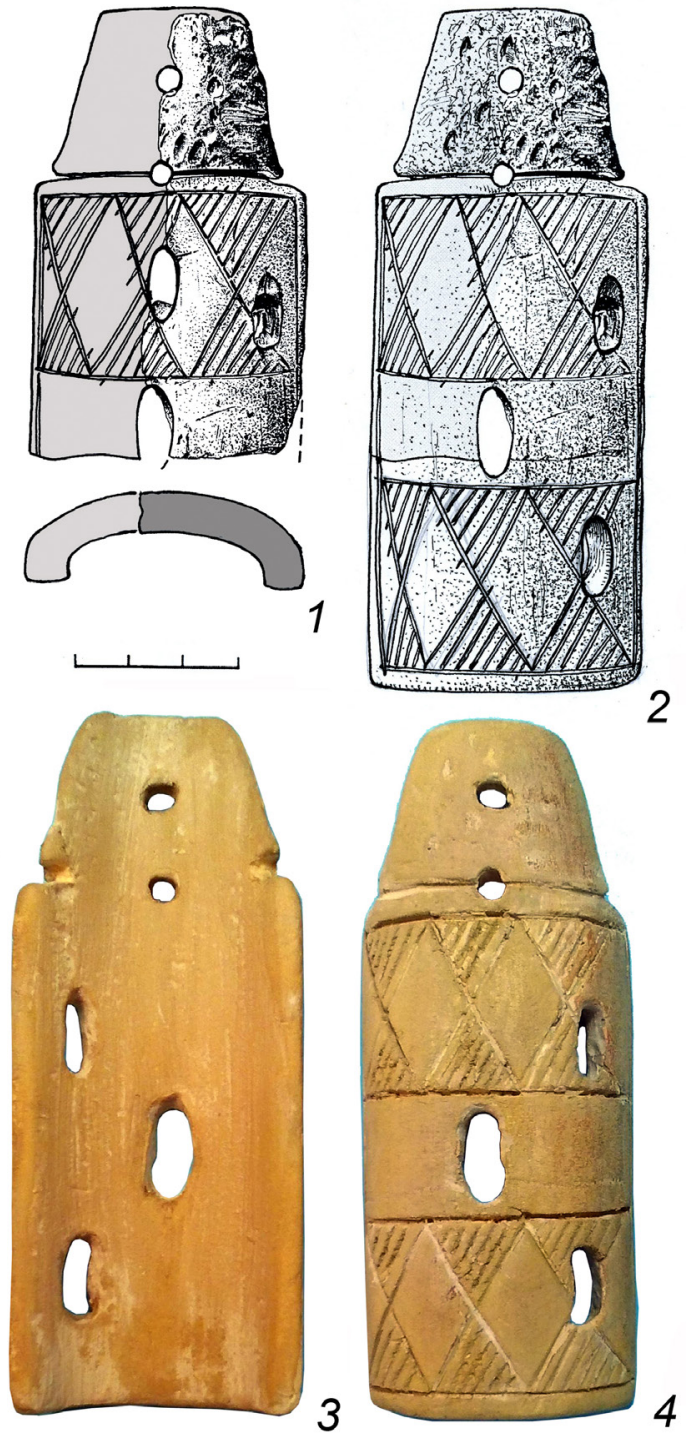

Рис. 2. Этапы реконструкции Николаевского псалия:

1 - графическая реконструкция псалия до поломки вдоль щитка и планки; 2 - графическая реконструкция первоначального вида псалия; 3-4 - объемная реконструкция псалия из пеноплекса: внутренняя (3) и внешняя стороны (4)

Fig. 2. Stages of reconstruction of the Nikolaevka cheek piece: 1 - graphic reconstruction of the Nikolaevka cheek piece before it has been broken; 1 - graphic reconstruction of the initial view of the cheek piece; 3-4 - three-dimensional model of the cheek piece made of the extruded polystyrene foam: inner (3) and outer surfaces (4)

своим желобчатым поперечным сечением не подходит под описание «пластинчатый». Во-вторых, на нем - типичная планка и нет такого признака, как «оформление одного из их концов в виде цапфенного захвата» [Бочкарев, Кузнецов, 2019. C.51]. В-третьих, орнаментация николаевского изделия совсем не та, которая присуща большинству пластинчатых псалиев [Бочкарев, Кузнецов, 2019. С.51-52]. Таким образом, мы пришли к выводу, что первоначально у николаевского псалия не было двух центральных отверстий и поперечная (первая) поломка псалия пришлась почти посередине щитка, чуть ниже центра единственного центрального на тот момент отверстия (рис. 1,4 ). Исходя из верхней орнаментированной части щитка, положения сработанности бокового отверстия (рис. 1, 4Л) [Исмагил и др., 2009. С. 140] и размеров центрального отверстия, мы сделали графическую реконструкцию первоначального вида николаевского псалия (рис. 2, 2): с двумя почти симметричными зонами орнамента на щитке, с овальным центральным и двумя боковыми отверстиями [ср.: Исмагил и др., 2009. С. 140]. Таким образом, судя по реконструкции, первоначальная длина николаевского псалия находилась в пределах 12,8 см.

Помимо графической, была вырезана и объемная реконструкция псалия из экструдированного пенополистирола - пеноплекса (рис. 2, 3-4). Эта копия позволила нам более детально разобраться с креплением ремней. Дело в том, что мастер николаевского псалия сделал в планке только два небольших отверстия, расположив их вертикально (рис. 2, 2-4). При этом нижнее отверстие смещено на границу планки и щитка (рис. $1,3 E$ ). Крепление наносного ремня должно учитывать не только эти отверстия, но и боковые выступы на планке - по сохранившемуся левому (рис. 1, 3B) мы реконструировали такой же выступ и справа у основания планки. ${ }^{4}$

Поначалу мы пустили ремень поверх планки, крепко завязав его поперечным ремешком, который фиксировался боковыми выступами. В ремне же были проделаны два небольших отверстия, совпадающие с отверстиями в планке и через них пропущен еще один тонкий ремешок, завязанный узлом поверх наносного ремня. Для того, чтобы сделать маленькое отверстие в ремне, совпадающее с отверстием на стыке планки и щитка, пришлось удлинить наносный ремень на 1-1,2 см и он в значительной степени перекрыл орнамент из верхних треугольников. Но даже такой удлиненный ремень был слишком короток для того, чтобы поперечная завязка ремешком через боковые выступы планки прочно его держала. Удлинить же наносный ремень еще мешало верхнее боковое отверстие щитка и факт того, что мы почти перекрывали верхние треугольники орнамента. Поэтому такое крепление ремня к планке было признано неудачным, тем более, что техническое решение расположения отверстий в планке николаевского мастера наталкивало на иные соображения. ${ }^{5}$

В конце концов, нам, надеемся, удалось предложить непротиворечивую систему крепления ремня к планке, поскольку мы пришли к выво-

\footnotetext{
${ }^{4} \mathrm{O}$ важности боковых выступов на щитковых и желобчатых псалиях и сложности ситуации с ними в целом см.: [Усачук, 2001; 2013. C. 150-151].

${ }^{5}$ Если бы николаевский мастер подразумевал крепление наносного ремня поперечным ремешком и узлом через отверстия в ремне и планке, то мог расположить эти отверстия в планке немного выше. Правда, в таком случае верхнее отверстие было бы ближе к торцу планки и прочность ее оказалась бы меньше. Не желая сближать маленькие отверстия в планке и тем самым увеличивать зону концентрации напряжения между ними, мастер мог не делать отверстия друг под другом по одной линии, а просверлить ниже верхнего два отверстия в планке, сместив их в стороны боковых выступов. Расстояние между отверстиями планки увеличилось бы, что снизило бы напряжение, но тогда вместо двух в планке появилось бы третье отверстие, что тоже сказалось бы на ее прочности.
} 


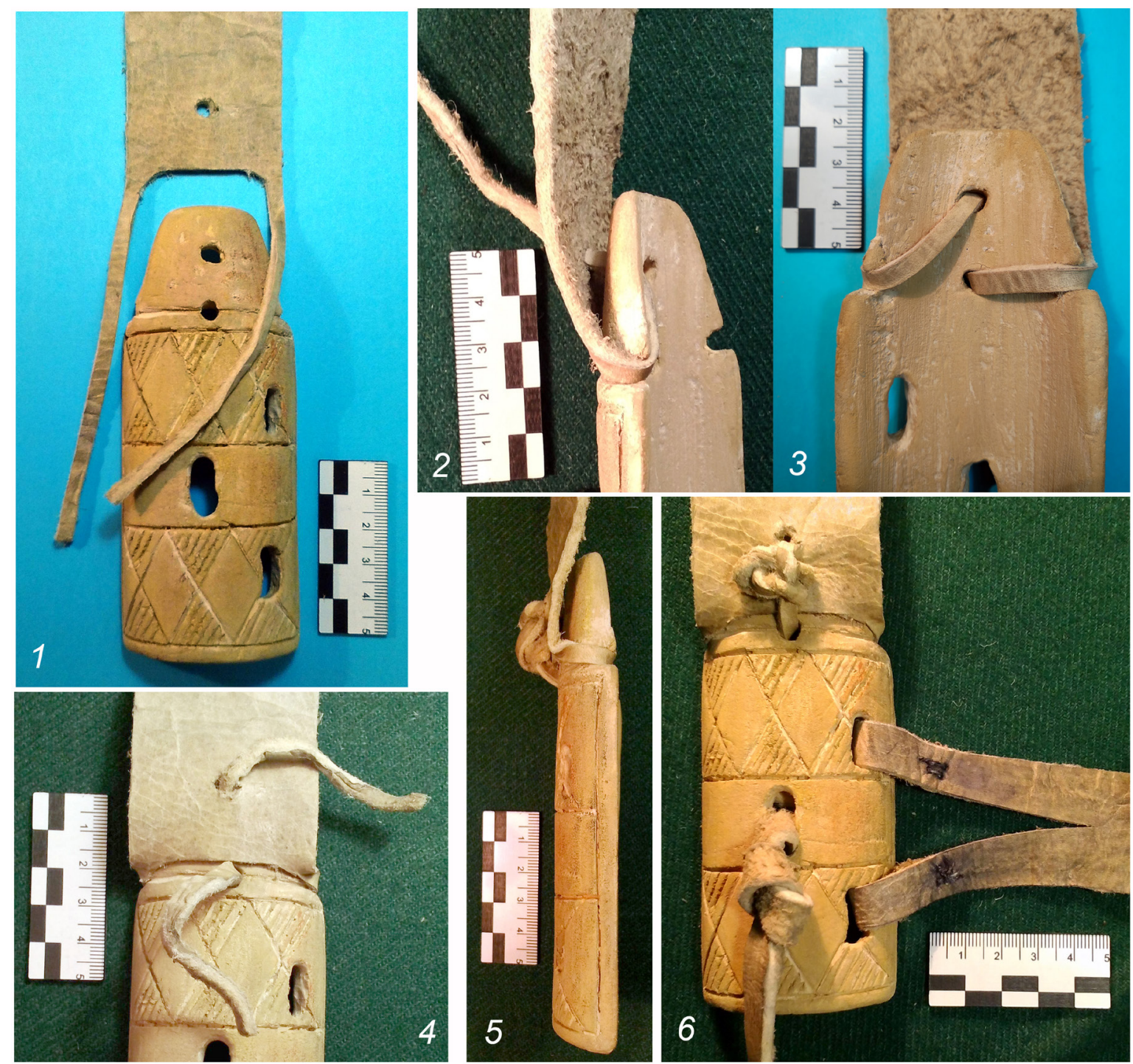

Рис. 3. Реконструкция системы крепления Николаевского псалия: 1 - реконструкция системы крепления концов наносного ремня к планке псалия; 2 - процесс крепления одного из концов наносного ремня к планке псалия; 3 - процесс крепления обоих тонких концов наносного ремня к планке псалия (внутренняя сторона); 4 - процесс крепления обоих тонких концов наносного ремня к планке псалия (внешняя сторона); 5 - процесс крепления обоих тонких концов наносного ремня к планке псалия (вид сбоку); 6 - реконструкция системы крепления наносного, нащечного ремня, грызла и повода на первоначальном псалии

Fig. 3 Reconstruction of the fastening system of the Nikolaevka cheek piece: 1 - reconstruction of the fastening system of the noseband ends to the check piece lug; 2 - the process of fastening one of the noseband ends to the check piece lug; 3 - the process of fastening both noseband ends to the check piece lug (inner surface); 4 - the process of fastening both noseband ends to the check piece lug (outer surface); 5 - the process of fastening both noseband ends to the check piece lug (side view); 6 - reconstruction of the fastening system of the noseband, throatlash, mouthpiece and reins at the original cheek piece

ду, что концы наносного ремня были утончены (рис. 3, 1). Один тонкий конец ремня захлестывался через выступ и шел в верхнее отверстие планки (рис. 3,2$)$. Другой - шел горизонтально и вдевался изнутри в нижнее отверстие планки (рис. 3, 3). При подобном креплении стало ясно, почему мастер сделал нижнее маленькое отверстие на стыке планки и щитка. Это позволяет проделывать в кожаном наносном ремне только одно отверстие, потому что второй тонкий конец выводится на лицевую сторону псалия только через отверстие планки чуть ниже обреза ремня (рис. 3,4$).{ }^{6}$ Концы тонких ремешков связываются (рис. 3,5 ) и прочно удерживают ремень на планке. Нащечный ремень, раздваиваясь, крепится к боковым отверстиям, мягкое грызло выходит своей петлей в центральное отверстие щитка и к этой петле крепится повод (рис. 3, б). ${ }^{7}$

\footnotetext{
${ }^{6}$ Таким образом, николаевский мастер не только обошел проблему слишком большого ослабления планки, но и лишний раз не стал перфорировать ремень. Ср. с выводом, что: «Во всех регионах псалии изготовлялись мастерами-профессионалами. Вероятнее всего, это не были узкие специалисты, делавшие только сами псалии. ... мастера изготавливали полностью упряжь (полностью - колесницу?), работая как с костью/рогом и деревом, так и с кожей» [Усачук, 2013. С. 115].

${ }^{7}$ Обратим внимание на то, что И.В. Чечушков на основе экспериментов с репликами древних псалиев приходит к нескольким выводам, один из которых звучит: «Наиболее эффективным методом изготовления ремней оголовья является плетение. .... Это позволяет ... сделать конструкцию простой, надежной и эффективной» [Чечушков, 2007. С. 426]. Мы последовали за И.В. Чечушковым чуть ранее, чем стали работать с николаевскис псалием, сделав наносный ремень плетеным для копии пары псалиев из могильника Обилькин Луг-ІІІ (рис. 4, 1) (голова лошади вырезана из пеноплекса). Если предположить, что и с николаевским псалием был плетеный наносный ремень, то мы имеем не два тонких окончания плоского ремня, а такие же два тонких ремешка, которые затем сплетаются друг с другом. На наш взгляд, возможны варианты.
} 

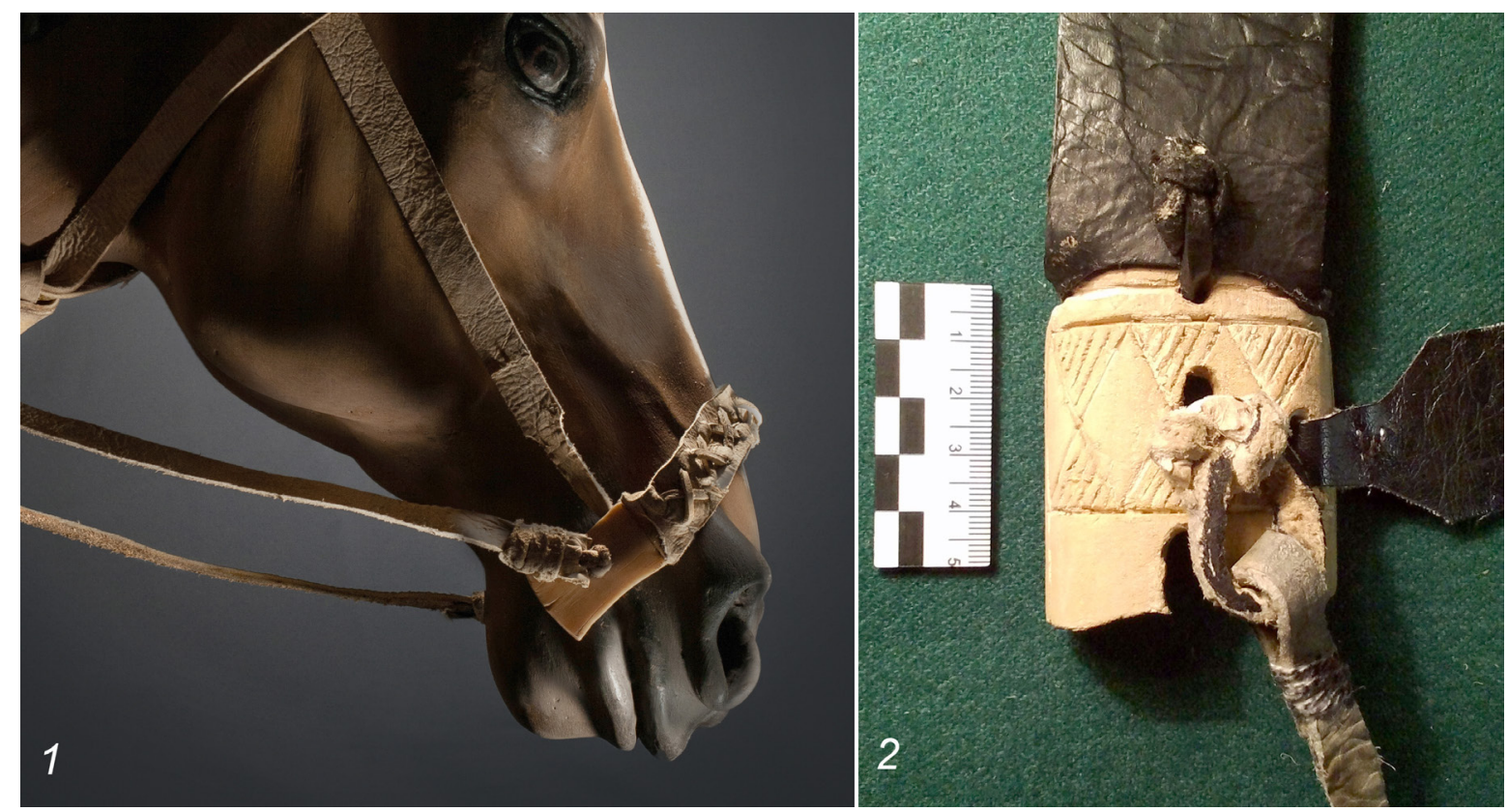

Рис. 4. Реконструкция узды с костяными псалиями:

1 - объемная реконструкция крепления копий пары псалиев из могильника Обилькин Луг-ІІІ с плетеным наносным ремнем 2 - реконструкция системы крепления наносного, нащечного ремня, грызла и повода на Николаевском псалии после его первой поломки и ремонта

Fig. 4. Reconstruction of the bridle with bone cheek pieces:

1 - three-dimensional model of the fastening system of the cheek pieces from the necropolis of Obilkin Lyg-III with the braided noseband; 2 - reconstruction of the fastening system of the noseband, throatlash, mouthpiece and reins at the Nikolaevka cheek piece after it was broken and repaired

Эксплуатация (впрочем, не слишком длительная), непредвиденные и неравномерные нагрузки привели к тому, что псалий все-таки сломался, но не вдоль (планка, к чести мастера, осталась цела), а поперек щитка. Подобное действительно могло произойти из-за индивидуальной характеристики лошади [Чечушков, 2007. С. 427]. Верхнюю часть щитка с планкой попытались, как мы говорили выше, превратить в новый псалий (рис. 2,1 ), сделав в щитке еще одно центральное отверстие. Мы пошли тем же путем: сломали копию так же, как псалий лопнул в древности и прорезали такое же овальное отверстие в щитке. Это было сделано для того, чтобы более наглядно представить крепление «нового» николаевского псалия (рис. 4,2$).$ Ранее мы предположили, что новая модификация николаевского псалия (рис. 2,1) работала непродолжительное время [Исмагил и др., 2009. С. 140]. Видимо, так и было, судя по тому, что в центре нового щитка очень неравномерно распределялась концентрация напряжений, о чем упоминалось выше. Использование сохранившегося бокового отверстия тоже, на наш взгляд, сыграло определенную, пусть и небольшую роль в новой поломке псалия, поскольку поперек щитка действовало усилие от натяжения уже не раздвоенного нащечного ремня (рис. 4,2 ).

\section{Вместо заключения: типологическое}

\section{определение николаевского псалия}

Николаевский псалий до поломок (рис. 2, 2-4) по предложенной десять лет назад и оказавшейся удачной классификации желобчатых псалиев на- иболее близок усатовскому типу [Бочкарев, Кузнецов, 2010. С. 303-306, 336-338]: «Желобчатые бесшипные псалии с несколькими отверстиями на планке и с одним, или двумя боковыми отверстиями на щитке» [Бочкарев, Кузнецов, 2010. С. 305]. Самая близкая аналогия среди псалиев усатовского типа - псалий с поселения Чишминское (Башкортостан) [Усачук, 2013. Рис. 97, 4], имеющий два вертикально расположенные маленькие отверстия в невыделенной планке и два боковых отверстия в щитке выше и ниже центрального. К усатовскому типу относится и псалий с Мосоловского поселения (Средний Дон), который, как указывают исследователи, «выделяется рядом особенностей» [Бочкарев, Кузнецов, 2010. С. 337], имея два маленьких отверстия на планке по продольной оси. Этими отверстиями мосоловский псалий наиболее близок и к чишминскому, и к николаевскому, но отверстия в щитке, помимо центрального, расположены не вдоль, а поперек щитка [Бочкарев, Кузнецов, 2010. Рис. 3,1$]$. Имея невыделенную планку, и чишминский, и мосоловский псалии как раз и скреплялись с наносным ремнем обычным способом: ремень накладывался на верхнюю часть псалиев, небольшой тонкий ремешок продевался через два отверстия в ремне и планке и завязывался узлом. При таком положении края наносного ремня возможно и дополнительное крепление - обмотка ремня для более плотного прилегания к поверхности псалия. ${ }^{8}$ Обратим внимание на еще один псалий усатовского типа - с острова Шелыган на Дону [Бочкарев, Кузнецов, 2010. Рис.2, 1]. У находки

\footnotetext{
${ }^{8}$ Именно возможность более прочного крепления наносного ремня позволяет нам предполагать, что этот ремень шел поверх псалия. Если завести край наносного ремня на внутреннюю часть и чишминского, и мосоловского псалиев, поперечная обмотка ничего не даст из-за желобчатого профиля обоих изделий, особенно чишминского.
} 
отсутствует почти вся планка [Бочкарев, Кузнецов, 2010. С.337], но, если предположить, что на ней были два вертикально расположенных маленьких отверстия, то, судя по сохранившимся желобкам в основании планки, крепление наносного ремня могло быть такое же, как предлагается нами для николаевского псалия (рис. $3,1,3) .{ }^{9}$

\section{СПИСОК ЛИТЕРАТУРЫ}

БородовскийА.П. Древнее косторезное дело юга Западной Сибири (вторая половина IIтыс. дон.э. - первая половина ІІтыс. н.э.). Новосибирск: Институт археологии и этнографии СО PAH, 1997. $225 \mathrm{c}$.

Бочкарев В.С., Кузнеияов П.Ф. Желобчатые псалии эпохи поздней бронзы евразийских степей // Кони, колесницы и колесничие степей Евразии. Коллективная монография / Гл. ред. П.Ф.Кузнецов. Екатеринбург, Самара, Донецк: Рифей, 2010. C. 292-343.

Бочкарев В.С., Кузнецов П.Ф. Об одной разновидности псалиев эпохи поздней бронзы Восточной Европы // Археология Восточно-Европейской степи. Вып. 15 / Под ред. В.А. Лопатина. Саратов: СГУ, 2019. С. 44-58.

Исмагил Р., МорозовЮ.А., Чапльгин М.С. Николаевские курганы («Елена») на реке Стерля в Башкортостане. Уфа: ДизайнПолиграфСервис, 2009. $240 \mathrm{c}$.

Куфтерин В.В., НечвалодаА.И. Палеоантропология Николаевского курганного могильника (по материалам 2004-2006гг.) // Р.Исмагил, Ю.А. Морозов, М.С. Чаплыгин. Николаевские курганы («Елена») на реке Стерля в Башкортостане. Уфа: ДизайнПолиграфСервис, 2009. С. 175-210.

Морозов Ю.А. Новые материалы, отражающие срубно-алакульские связи // Этнические взаимодействия на Южном Урале: Материалы III регион. (с междунар. участием) науч.-практ. конф. Челябинск: ЧелГУ, 2006. С. 58-61.

Морозов Ю.А., Чаплыгин М.С. Срубные погребения Николаевского могильника // Уфимский археологический вестник. Вып. 6-7. 2007. С. 50-61.
Сатаев Р.M. Остатки животных из раскопок 1 и 2 курганов Николаевского могильника // Р. Исмагил, Ю.А. Морозов, М.С. Чаплыгин. Николаевские курганы («Елена») на реке Стерля в Башкортостане. Уфа: ДизайнПолиграфСервис, 2009. С.211221.

Сатаев Р.М., ГимрановД.О. Характеристика археозоологического материала из 7 кургана Николаевского могильника // Р. Исмагил, Ю.А. Морозов, М.С. Чаплыгин. Николаевские курганы («Елена») на реке Стерля в Башкортостане. Уфа: ДизайнПолиграфСервис, 2009. С. 222-228.

Сулейманов Р.P. Характеристика почвенного покрова Николаевского могильника // Р.Исмагил, Ю.А. Морозов, М.С. Чаплыгин. Николаевские курганы («Елена») на реке Стерля в Башкортостане. Уфа: ДизайнПолиграфСервис, 2009. С. 229-239.

УсачукА.Н. Конструктивные особенности планок щитковых псалиев // Проблемы археологии и архитектуры. Т. 1. Археология. Донецк, Макеевка: Донбасс, 2001. С. 105-111.

УсачукА.Н. Древнейшие псалии (изготовление и использование). Киев, Донецк: ИА НАНУ, 2013. 304c.

УсачукА.Н. Костяные и роговые изделия из погребений кургана 2 Липецкого могильника // Липецкий курган - памятник элиты доно-волжской абашевской культуры / Научные труды ООО НПО «Черноземье». Вып. 4 / Отв. ред. А.Н. Усачук. Липецк, Воронеж: «Новый взгляд», 2016. С. 23-34.

Чечушков И.В. Оголовье колесничной лошади эпохи бронзы: экспериментальное исследование // Проблемы истории, филологии, культуры. 2007. Вып. XVII. C.421-428.

\section{REFERENCES}

Borodovsky,A.P. 1997, Ancient art of bone carving in the South part of Western Siberia (the second half of the $2^{\text {nd }}$ millennium $B C$ - the first half of the $2^{\text {nd }}$ millennium $A D$ ). Institute of Archeology and Ethnography SB RAS, Novosibirsk, 225 p. (In Russ.)

Bochkarev, V.S., Kuznetsov,P.F. "Grooved cheekpieces of the Late Bronze Age from Eurasian steppes", Koni, kolesnicy i kolesnichie stepej Evrazii. Kollektivnaya monografiya, ("Horses, chariots and charioteers of the steppes of Eurasia. A collective monograph"). Yekaterinburg, Samara, Donetsk, 2010, pp. 292-343. (In Russ.)

Bochkarev, V.S., Kuznetsov, P.F. 2019, “About one variety of cheekpieces of the Late Bronze Age from Eastern Europe", Archeology of Eastern European Steppe, vol. 15, pp. 44-58. (In Russ.)

Ismagil R., Morozov, Y.A., \& Chaplygin, M.S. 2009, Barrows of Nikolaevka ("Elena") at the Sterlya river in Bashkortostan. DesignPoligrafService, Ufa, 240 p. (In Russ.)

Kufterin, V.V., Nechvaloda,A.I. "Paleoanthropology of Nikolaevsky barrow necropolis (based on the assemblages of 2004-2006)", IsmagilR., Morozov, Y.A., \& Chaplygin, M.S. 2009, Barrows of Nikolaevka ("Elena") at the Sterlya river in Bashkortostan. DesignPoligrafService, Ufa, pp. 175-210. (In Russ.)

Morozov, Y.A. "New finds, reflecting the Srub-

\footnotetext{
${ }^{9}$ К сожалению, псалий с острова Шелыган не обработан трасологически, но, исходя из рисунка, мы можем предположить, что сохранившиеся желобки в основании планки этого псалия вторичны. Если это так, то планка ломалась дважды: сначала что-то случилось с боковыми выступами первоначальной планки, но сохранились на ней маленькие отверстия - только таким способом можно объяснить наличие новых желобков ниже основания планки. Через какое-то время сломалась вся планка и псалий был оставлен.
} 
naya and Alakul cultures' interactions", Etnicheskie vzaimodejstviya na Yuzhnom Urale: materialy III region. (s mezhdunar. uchastiem) nauch.-prakt. konf. ("Ethnic interactions in the Southern Urals: Proceedings of the $3^{\text {rd }}$ regional (with the foreign participants) scientific and practical conference"). Chelyabinsk, 2006, pp. 58-61. (In Russ.)

Morozov, Y.A., Chaplygin, M.S. 2007, "The Srubnaya culture burials on the territory of Nikolaevsky necropolis", The Ufa Archaeological Herald, vol. 6-7, pp. 50-61. (In Russ.)

Sataev, R.M. "Animal bone remains from the excavations of the $1^{\text {st }}$ and $2^{\text {nd }}$ barrows of Nikolaevsky necropolis", IsmagilR., Morozov,Y.A., \& Chaplygin, M.S. 2009, Barrows of Nikolaevka ("Elena") at the Sterlya river in Bashkortostan. DesignPoligrafService, Ufa, pp. 211-221. (In Russ.)

Sataev, R.M., Gimranov, D.O. "Characteristics of the archeozoological finds from the $7^{\text {th }}$ barrow of Nikolaevsky necropolis", Ismagil R., Morozov, Y.A., \& Chaplygin, M.S. 2009, Barrows of Nikolaevka ("Elena") at the Sterlya river in Bashkortostan. DesignPoligrafService, Ufa, pp. 222-228. (In Russ.)

Suleymanov, R.R. "Characteristics of the soil cover at Nikolaevsky necropolis", Ismagil R., Morozov, Y.A., \& Chaplygin, M.S. 2009, Barrows of Nikolaevka ("Elena") at the Sterlya river in Bashkortostan. DesignPoligrafService, Ufa, pp.229-239. (In Russ.)

Usachuk,A.N. "Structural features of the snaffles of shield cheeckpieces", Problemy arheologii i arhitektury. T.1. Arheologiya. ("Problems of archeology and architecture, vol. 1. Archeology"). Donetsk, Makeyevka, 2001, pp. 105-111. (In Russ.)

Usachuk,A.N. 2013, Ancient cheeckpieces (production and use). IA NASU, Kiev, Donetsk, 304 p. (In Russ.)

Usachuk,A.N. "Bone and horn items from the burials of the barrow 2 of the Lipetsk necropolis", Lipeckij kurgan - pamyatnik elity dono-volzhskoj abashevskoj kul'tury ("Lipetsk barrow - an archaeological site related to the elite of the Don-Volga Abashevo culture"). Lipetsk, Voronezh, 2016, pp.23-34. (In Russ.)

Chechushkov, I.V. 2007, "Headstall of a Bronze Age chariot horse: an experimental study", Problems of history, philology, culture, iss. 17, pp.421-428. (In Russ.)

\section{Сведения об авторах}

Юрий Алексеевич Морозов, кандидат исторических наук, независимый исследователь. Российская Федерация, г. Уфа. E-mail: morozovua1941@gmail.com, ORCID 0000-0001-7630-4017

Михаил Сергеевич Чаплыгин, научный сотрудник. Стерлитамакский историко-краеведческий музей, Российская Федерация, г. Стерлитамак. E-mail: msch1979@gmail.com, ORCID 0000-0002-32960175

Анатолий Николаевич Усачук, кандидат исторических наук, старший научный сотрудник. Донецкий краеведческий музей, Украина, г. Донецк. E-mail: doold@mail.ru / ORCID 0000-0002-1028-1884

Андрей Валерьевич Вербовский, старший научный сотрудник. Донецкий краеведческий музей, Украина, г. Донецк. E-mail: verbovskiyy@ro.ru, ORCID 0000-0002-2171-4462

\section{Information About the Authors}

Yuri A. Morozov, Ph.D., independent researcher. Russian Federation, Ufa. E-mail: morozovua1941@ gmail.com, ORCID 0000-0001-7630-4017

Mikhail S. Chaplygin, researcher. Sterlitamak Museum of Local Lore. Russian Federation, Sterlitamak. E-mail: msch1979@gmail.com, ORCID 0000-0002-3296-0175

Anatoly N. Usachuk, Ph.D., senior researcher. Donetsk Museum of Local Lore, Ukraine, Donetsk. E-mail: doold@mail.ru, ORCID 0000-0002-1028-1884

Andrey V. Verbovsky, senior researcher. Donetsk Museum of Local Lore, Ukraine, Donetsk. E-mail: verbovskiyy@ro.ru, ORCID 0000-0002-2171-4462 